\title{
What does galvanic vestibular stimulation actually activate: response
}

\section{Bernard Cohen ${ }^{1}$, Sergei B. Yakushin ${ }^{1}$ and Gay R. Holstein ${ }^{1,2,3}$ \\ 1 Departments of Neurology, Mount Sinai School of Medicine, New York, NY, USA \\ 2 Departments of Neuroscience, Mount Sinai School of Medicine, New York, NY, USA \\ ${ }^{3}$ Department of Anatomy/Functional Morphology, Mount Sinai School of Medicine; New York, NY, USA \\ ${ }^{*}$ Correspondence: bernard.cohen@mssm.edu}

Edited by:

Sergio Carmona, Instituto de Neurociencias de Buenos Aires, Argentina

Reviewed by:

Sergio Carmona, Instituto de Neurociencias de Buenos Aires, Argentina
Curthoys and MacDougall (2012) question the conclusion that galvanic vestibular stimulation (GVS) predominantly activates the otolith system. They have demonstrated that strong $(5 \mathrm{~mA})$ GVS applied continuously to alert humans in darkness causes weak nystagmus, with average velocities of about $5 \%$ (MacDougall et al., 2002, 2003, 2005). This nystagmus undoubtedly originated from activation of the semicircular canals. They claim that this refutes our general conclusion that the predominant activation of the vestibular system during GVS is through the otolith system, a conclusion based on a wide range of studies in which GVS induced a sense of roll, ocular counter-torsion, postural sway, and body tilt but not nystagmus, vertigo, or a sense of rotation. The results were uniform across these diverse studies, although some were conducted in darkness or with the eyes closed. They also question conclusions based on an anatomic demonstration by Holstein et al. (2012) that c-fos activation was essentially located in otolithdriven, vestibulo-sympathetic neurons in the vestibular nuclei (Holstein et al., 2012). Curthoys has made many important contributions to elucidating semicircular canal and otolith anatomy and physiology, but we believe that he and MacDougall are not correct in this issue.

Important evidence for our conclusion derives from a compendium of studies by Macefield and colleagues showing that sinusoidal GVS is a potent stimulus for induction of muscle sympathetic nerve activity (MSNA); a reflection of otolith activation. In these studies, currents of $2 \mathrm{~mA}$ induced a sense of rolling but never rotation or vertigo (Bent et al., 2006; Grewal and James, 2009; James and Macefield, 2010; James et al.,
2010; Hammam et al., 2011, 2012; Grewal et al., 2012). The sense of roll is consistent with a host of other studies using GVS (Fitzpatrick et al., 1994; Inglis et al., 1995; Day et al., 1997; Zink et al., 1997; Day and Cole, 2002; Scinicariello et al., 2002/2003; Wardman et al., 2003a,b; see Fitzpatrick and Day, 2004 for review). Modeled on this research, we used 2-3 mA currents in lightly anesthetized rats and found strong activation of the sympathetic nervous system and vasovagal responses, but not tonic deviations of the eyes (Cohen et al., 2011). We have also stimulated the vestibular nerve with trains of pulses to activate MSNA in humans (Voustianiouk et al., 2006), sometimes utilizing currents of $5 \mathrm{~mA}$. MSNA was facilitated, but ocular deviations were never induced.

The semicircular canals can exert a powerful influence on eye movements through the vestibulo-ocular reflex. Head turns induce eye movements with velocities of up to $400 \%$ s (Atkin and Bender, 1968), and with response characteristics up to $20 \mathrm{~Hz}$ (Grossman et al., 1988; Tabak and Collewijn, 1994; Armand and Minor, 2001). Furthermore, a change in body temperature of only $7^{\circ} \mathrm{C}$ during caloric stimulation with either air or water readily induces nystagmus with slow phase velocities of $30-40 \%$ in monkeys (Arai et al., 2002) and $10-20 \%$ in humans (M. Dai, personal communication). Thus, at best, the semicircular canal activation induced using strong GVS by Curthoys and MacDougall, which produced average slow phase eye velocities of $5 \% \mathrm{~s}$, was weak and functionally inconsequential.

The question of function is particularly relevant in this regard. The semicircular canals stabilize gaze in space during head movement through what is probably the fastest reflex in the body. That is, electrical stimulation of canal nerves can activate eye muscles in $1.5 \mathrm{~ms}$, which would potentially allow for a frequency response of $600 \mathrm{~Hz}$ (Cohen and Suzuki, 1963). In actuality, eye muscles were driven at $400 \mathrm{~Hz}$ and prominent nystagmus with large beats and high velocity were induced by semicircular canal nerve stimulation (Cohen et al., 1965). The canals also activate neck muscles at short latencies to help stabilize the head in space (Denise et al., 1987; Xiang et al., 2008). On the other hand, the otolith organs, while having a small direct ocular response to sharp increases in linear acceleration of the head (Paige and Tomko, 1991), do not produce nystagmus and there is only weak ocular torsion of about $4^{\circ}$ from vestibular nerve stimulation that orients the eyes to the spatial horizontal in frontal-eyed species, including humans. Thus, the otolith system appears not to be primarily directed toward controlling eye movements in humans, although one can get small rapid eye movements from rapid head movements (Curthoys, 2010). Rather, the otolith system appears to be more involved in orientation in space, in activation of the vestibulo-sympathetic reflex, and in stabilization of posture, none of which are functions of the semicircular canals.

Therefore we conclude that our previous reply to Dr. Colebatch and our original letter in which we stated that while there may be weak semicircular canal activation, the response to GVS is predominantly otolithic in function are correct, and we do not find the Curthoys and MacDougall argument sufficiently compelling to refute our conclusion. 


\section{REFERENCES}

Arai, Y., Yakushin, S. B., Cohen, B., Suzuki, J.-I., and Raphan, T. (2002). Spatial orientation of caloric nystagmus in semicircular canal-plugged monkeys. J. Neurophysiol. 88, 914-928.

Armand, M., and Minor, L. B. (2001). Relationship between time- and frequency-domain analyses of angular head movements in the squirrel monkey. J. Comput. Neurosci. 11, 217-239.

Atkin, A., and Bender, M. B. (1968). Ocular stabilization during oscillatory head movements. Arch. Neurol. 19, 559-566.

Bent, L. R., Bolton, P. S., and Macefield, V. G. (2006). Modulation of muscle sympathetic bursts by sinusoidal galvanic vestibular stimulation in human subjects. Exp. Brain Res. 174, 701-711.

Cohen, B., Martinelli, G. P., Ogorodnikov, D., Xiang, Y., Raphan, T., Holstein, G. R., et al. (2011). Sinusoidal galvanic vestibular stimulation (sGVS) induces a vasovagal response in the rat. Exp. Brain Res. 210 45-55.

Cohen, B., Suzuki, J., and Bender, M. B. (1965). Nystagmus induced by electric stimulation of ampullary nerves. Acta Otolaryngol. 60, 422-436.

Cohen, B., and Suzuki, J. I. (1963). Eye movement induced by ampullary nerve stimulation. Am. J. Physiol. 204, 347-351.

Curthoys, I. S. (2010). A critical review of the neurophysiological evidence underlying clinical vestibular testing using sound, vibration and galvanic stimuli. Clin. Neurophysiol. 121, 132-144.

Curthoys, I. S., and MacDougall, H. G. (2012). What galvanic vestibular stimulation actually activates. Front. Neurol. 3, 117. doi: 10.3389/fneur.2012.00117

Day, B. L., and Cole, J. (2002). Vestibular-evoked postural responses in the absence of somatosensory information. Brain 125(Pt 9), 2081-2088.

Day, B. L., Séverac Cauquil, A., Bartolomei, L., Pastor, M. A., and Lyon, I. N. (1997). Human body-segment tilts induced by galvanic stimulation: a vestibularly driven balance protection mechanism. J. Physiol. (Lond.) 500(Pt 3), 661-672.

Denise, P., Darlot, C., Wilson, V. J., and Berthoz, A. (1987). Modulation by eye position of neck muscle contraction evoked by electrical labyrinthine stimulation in the alert cat. Exp. Brain Res. 67, 411-419.

Fitzpatrick, R., Burke, D., and Gandevia, S. C. (1994). Task-dependent reflex responses and movement illusions evoked by galvanic vestibular stimulation in standing humans. J. Physiol. (Lond.) 478(Pt 2), 363-372.
Fitzpatrick, R. C., and Day, B. L. (2004). Probing the human vestibular system with galvanic stimulation. J. Appl. Physiol. 96, 2301-2316.

Grewal, T., Dawood, T., Hammam, E., Kwok, K., and Macefield, V. G. (2012). Low-frequency physiological activation of the vestibular utricle causes biphasic modulation of skin sympathetic nerve activity in humans. Exp. Brain Res. 220, 101-108.

Grewal, T., and James, C. (2009). Frequency-dependent modulation of muscle sympathetic nerve activity by sinusoidal galvanic vestibular stimulation in human subjects. Exp. Brain Res. 197, 379-386.

Grossman, G. E., Leigh, R. J., Abel, L. A., Lanska, D. J., and Thurston, S. E. (1988). Frequency and velocity of rotational head perturbations during locomotion. Exp. Brain Res. 70, 470-476.

Hammam, E., Dawood, T., and Macefield, V. G. (2012) Low-frequency galvanic vestibular stimulation evokes two peaks of modulation in skin sympathetic nerve activity. Exp. Brain Res. 219, 441-446.

Hammam, E., James, C., Dawood, T., and Macefield, V. G. (2011). Low-frequency sinusoidal galvanic stimulation of the left and right vestibular nerves reveals two peaks of modulation in muscle sympathetic nerve activity. Exp. Brain Res. 213, 507-514.

Holstein, G. R., Friedrich, V. L. J., Martinelli, G. P., Ogorodnikov, D., Yakushin, S. B., and Cohen, B. (2012). Fos expression in neurons of the rat vestibuloautonomic pathway activated by sinusoidal galvanic vestibular stimulation. Front. Neurol.3:4. doi: 10.3389/ fneur.2012.00004

Inglis, J. T., Shupert, C. L., Hlavacka, F., and Horak, F. B. (1995). Effect of galvanic vestibular stimulation on human postural responses during support surface translations. J. Neurophysiol. 73, 896-901.

James, C., and Macefield, V.G. (2010). Competitive interactions between vestibular and cardiac rhythms in the modulation of muscle sympathetic nerve activity. Auton. Neurosci. 158, 127-131.

James, C., Stathis, A., and Macefield, V. G. (2010) Vestibular and pulse-related modulation of skin sympathetic nerve activity during sinusoidal galvanic vestibular stimulation in human subjects. Exp. Brain Res. 202, 291-298.

MacDougall, H. G., Brizuela, A. E., Burgess, A. M., and Curthoys, I.S. (2002). Between-subject variability and within-subject reliability of the human eye-movement response to bilateral galvanic (DC) vestibular stimulation. Exp. Brain Res. 144, 69-78.

MacDougall,H.G., Brizuela,A.E., Burgess,A.M., Curthoys, I. S., and Halmagyi, G. M. (2005). Patient and normal three-dimensional eye-movement responses to main- tained (DC) surface galvanic vestibular stimulation. Otol. Neurotol. 26, 500-511.

MacDougall, H. G., Brizuela, A. E., and Curthoys, I. S. (2003). Linearity, symmetry and additivity of the human eye-movement response to maintained unilateral and bilateral surface galvanic (DC) vestibular stimulation. Exp. Brain Res. 148, 166-175.

Paige, G. D., and Tomko, D. L. (1991). Eye movement responses to linear head motion in the squirrel monkey. I. Basic characteristics. J. Neurophysiol. 65, 1170-1182.

Scinicariello, A. P., Inglis, J. T., and Collins, J.J. (2002/2003). The effects of stochastic monopolar galvanic vestibular stimulation on human postural sway. J. Vestib. Res. $12,77-85$.

Tabak, S., and Collewijn, H. (1994). Human vestibuloocular responses to rapid, helmet-driven head movements. Exp. Brain Res. 102, 367-378.

Voustianiouk, A., Kaufmann, H., Diedrich,A., Raphan, T., Biaggioni, I., MacDougall, H., et al. (2006). Electrical activation of the human vestibulo-sympathetic reflex. Exp. Brain Res. 171, 251-261.

Wardman, D. L., Day, B. L., and Fitzpatrick, R. C. (2003a). Position and velocity responses to galvanic vestibular stimulation in human subjects during standing. J. Physiol. (Lond.) 547(Pt 1), 293-299.

Wardman, D. L., Taylor, J. L., and Fitzpatrick, R. C. (2003b). Effects of galvanic vestibular stimulation on human posture and perception while standing. J. Physiol. (Lond.) 551(Pt 3), 1033-1042.

Xiang, Y., Yakushin, S. B., Kunin, M., Raphan, T., and Cohen, B. (2008). Head stabilization by vestibulocollic reflexes during quadrupedal locomotion in monkey. J. Neurophysiol. 100, 763-780.

Zink, R., Steddin, S., Weiss, A., Brandt, T., and Dieterich, M. (1997). Galvanic vestibular stimulation in humans: effects on otolith function in roll. Neurosci. Lett. 232, 171-174.

Received: 13 September 2012; accepted: 01 October 2012 published online: 22 October 2012.

Citation: Cohen B, Yakushin SB and Holstein GR (2012)

What does galvanic vestibular stimulation actually activate: response. Front. Neur. 3:148. doi: 10.3389/fneur.2012.00148 This article was submitted to Frontiers in Neuro-otology, a specialty of Frontiers in Neurology.

Copyright (C) 2012 Cohen, Yakushin and Holstein. This is an open-access article distributed under the terms of the Creative Commons Attribution License, which permits use, distribution and reproduction in other forums, provided the original authors and source are credited and subject to any copyright notices concerning any third-party graphics etc. 